06.1

\title{
Карбонизация нанокристаллического кремния с помощью фторуглерода
}

\author{
(C) Е.В. Астрова, В.П. Улин, А.В. Парфеньева, В.Б. Воронков \\ Физико-технический институт им. А.Ф. Иофрфе РАН, Санкт-Петербург, Россия \\ E-mail: east@mail.ioffe.ru
}

Поступило в Редакцию 2 апреля 2019г.

В окончательной редакции 5 апреля 2019г.

Принято к публикации 5 апреля 2019г.

\begin{abstract}
Предлагается новый способ создания пористых кремний-углеродных нанокомпозитов, использующий процесс восстановления монофторида углерода кремнием. Образующиеся композитные материалы формируются кремниевыми наночастицами, заключенными в углеродную оболочку. Контакты таких частиц обеспечивают протекание тока по возникающей углеродной матрице. Определены зависимости от состава плотности, пористости и удельного сопротивления полученных предложенным способом композитных таблеток $\mathrm{Si}-\mathrm{C}$. Исследованные материалы представляют интерес для создания отрицательных электродов литий-ионных аккумуляторов высокой емкости.
\end{abstract}

Ключевые слова: кремний-углеродные композиты, восстановление фторуглерода кремнием, нанокремний, пористые кремниевые аноды для литий-ионных аккумуляторов.

DOI: 10.21883/PJTF.2019.13.47954.17818

Нанокристаллический кремний даже с высоким уровнем легирования обладает чрезвычайно низкой электропроводностью, поскольку оборванные связи, имеющиеся на поверхности кремниевых частиц, создают глубокие электронные ловушки, связывающие практически все свободные носители заряда. В результате уровень Ферми оказывается привязан к энергетическому положению поверхностных состояний в середине запрещенной зоны полупроводника. В ряде случаев, когда востребованными оказываются Si-частицы малых размеров (например, в качестве материала отрицательных электродов литийионных аккумуляторов), отсутствие электропроводности становится основным препятствием к их практическому использованию [1,2]. Эта проблема может быть решена путем создания композитов нанокремния с углеродом [3]. Наиболее распространенным методом карбонизации кремниевых наночастиц является пиролитическое осаждение на них углерода из газообразных углеводородов и других органических веществ. Применение пиролитических методов не позволяет, однако, надежно контролировать количество и локализацию образовавшегося углерода.

В настоящей работе сообщается о новом простом способе карбонизации нанокремния путем взаимодействия его с полимерным монофторидом углерода $\left(\mathrm{CF}_{x}\right)_{n}$ [4]. Процесс включает компрессию смеси порошков $\mathrm{Si}$ и фторуглерода (для краткости $\mathrm{CF}_{x}$ ) и последующий отжиг полученной таблетки в инертной атмосфере при $T>600^{\circ} \mathrm{C}$. В ходе отжига происходит диспропорционирование $\mathrm{CF}_{x}$ с образованием летучих фторуглеродных соединений, взаимодействующих затем с частицами кремния. Развивающиеся в смеси гетерогенные реакции имеют экзотермический характер и приводят к практически полному восстановлению углерода из его фторидов. При этом прореагировавшая часть кремния удаляется из таблетки в виде газообразного $\mathrm{SiF}_{4}$. Поскольку реакции протекают на поверхности кремниевых частиц, вокруг каждой из них возникает углеродная оболочка, а при достаточном количестве выделившегося углерода происходит формирование в материале связанной токопроводящей сетки (рис. 1,a). Удаление образовавшегося $\mathrm{SiF}_{4}$ и произошедшее вследствие описанных процессов перераспределение масс в подвергнутой отжигу таблетке увеличивают ее общую пористость.

Для изготовления реакционных смесей использовался порошок нанодисперсного кремния, полученный методом термического разложения силана. Порошок состоял из конгломератов сферических частиц кристаллического кремния диаметром 30-50 nm. Исходный монофторид углерода, получаемый фторированием углей со структурой графита, представлял собой темно-серый порошок с зернами размером $0.3-5 \mu \mathrm{m}$. Кроме собственно монофторида углерода использованный материал содержал небольшое количество непрореагировавшего углерода, придававшего ему серый цвет. Порошки $\mathrm{Si}$ и фторуглерода, взятые в разных пропорциях, тщательно перемешивались и протирались в агатовой ступке. Из полученной смеси при давлении $180 \mathrm{MPa}$ прессовались таблетки диаметром $10 \mathrm{~mm}$. Спрессованные таблетки $\mathrm{Si}+\mathrm{CF}_{x}$ имели слоистую структуру и обладали более высокой прочностью, чем таблетки из чистого нанопорошка кремния [5].

До и после отжига измерялась толщина таблеток, производилось их взвешивание и фотографирование для определения реальной площади. Из полученных данных рассчитывалась плотность спрессованного материала $\rho$. Усредненная пористость таблетки оценивалась исходя из ее измеренной плотности по формуле $p=1-\rho / \rho_{\text {mix }}$, 

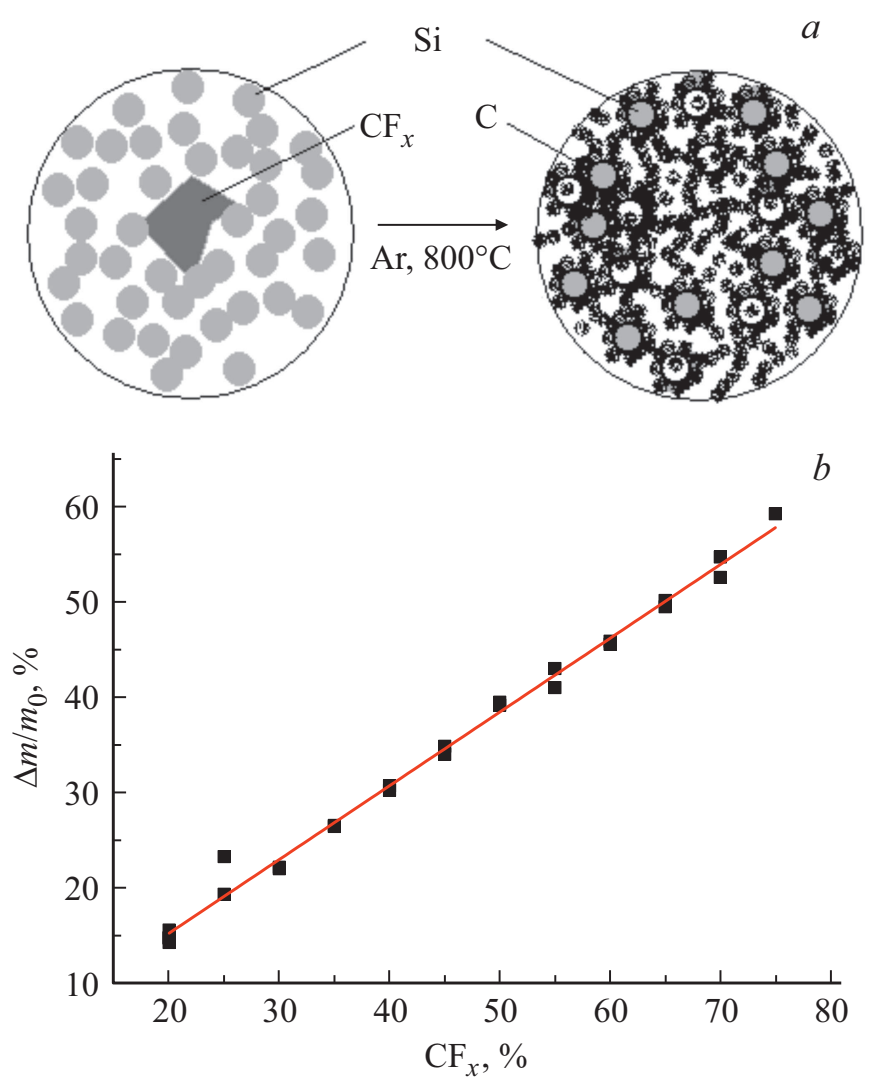

Рис. 1. $a-$ схема процесса карбонизации кремниевого нанопорошка при взаимодействии его с фторуглеродом; $b-$ потеря массы таблеток $\Delta m$ после отжига, нормированная на их массу до отжига $m_{0}$, в зависимости от массовой доли фторуглерода в исходной смеси.

где $\rho_{\text {mix }}$ - расчетные плотности компактных смесей известного состава: $\left(\mathrm{CF}_{x}+\mathrm{Si}\right)$ до отжига и $(\mathrm{C}+\mathrm{Si})$ после отжига. При расчете плотностей компактных смесей принимались следующие значения для плотности их компонентов: $\rho_{\mathrm{CF}_{x}}=2.94 \mathrm{~g} / \mathrm{cm}^{3}[4], \rho_{\mathrm{Si}}=2.33 \mathrm{~g} / \mathrm{cm}^{3}$, $\rho_{\mathrm{C}}=1.86 \mathrm{~g} / \mathrm{cm}^{3}$ (плотность сажи). Таблетки отжигались в квазизамкнутом объеме графитовых кассет. Кассеты помещались в муфельную печь с кварцевой трубой, продуваемой аргоном высокой чистоты и нагретой до $400^{\circ} \mathrm{C}$. Через $10 \mathrm{~min}$ осуществлялось медленное (в течение $2 \mathrm{~h}$ ) повышение температуры печи до $800^{\circ} \mathrm{C}$ с последующей выдержкой образцов в течение 20 min при этой температуре и охлаждением в течение $1 \mathrm{~h}$. После этого кассеты выдвигались в холодную часть трубы и извлекались на воздух.

После отжига масса таблеток значительно уменьшалась в результате образования газообразного тетрафторида кремния. Суммарную реакцию восстановления кремнием фторуглерода произвольного состава с атомным соотношением $\mathrm{F} / \mathrm{C}=x$ можно записать как

$$
(4 / x) \mathrm{CF}_{x}+\mathrm{Si}=\mathrm{SiF}_{4} \uparrow+(4 / x) \mathrm{C} .
$$

В пересчете на весовые соотношения и с учетом молекулярных масс реагентов

$$
(48 / x+76) \mathrm{CF}_{x}+28 \mathrm{Si}=104 \mathrm{SiF}_{4}+(48 / x) \mathrm{C} .
$$

На рис. 1, $b$ приведена зависимость относительной потери массы подвергшихся отжигу таблеток от их исходного состава. Экспериментально полученная зависимость хорошо аппроксимируется прямой с наклоном $k=0.772 \pm 0.013$. Из уравнения (2) следует, что этот наклон определяется отношением молекулярных масс образующегося тетрафторида кремния и исходного фторуглерода. В это отношение входит величина $x: k=104 /(48 / x+76)$, откуда $x=0.817$. Таким образом, исходному фторуглероду можно приписать бруттоформулу $\mathrm{CF}_{0.82}$. Тогда весовые проценты продуктов реакции, образовавшихся из смесей монофторида углерода и кремния с произвольной массовой долей $\mathrm{CF}_{x}$, равной $r$ и выраженной в процентах, можно представить как

$$
\begin{aligned}
r \mathrm{CF}_{0.82} & +(100-r) \mathrm{Si}=0.773 r \mathrm{SiF}_{4} \\
& +0.435 r \mathrm{C}+(100-1.208 r) \mathrm{Si},
\end{aligned}
$$

где количество выделившегося тетрафторида кремния составляет $0.773 r$, а углерода $-0.435 r$, тогда как член в скобках в правой части уравнения определяет количество непрореагировавшего $\mathrm{Si}$, остающегося в твердой фазе. На рис. 2, а приведено содержание углерода и кремния в отожженной таблетке в зависимости от количества фторуглерода в исходной смеси $\mathrm{CF}_{x}+\mathrm{Si}$, рассчитанное по уравнению (3). 


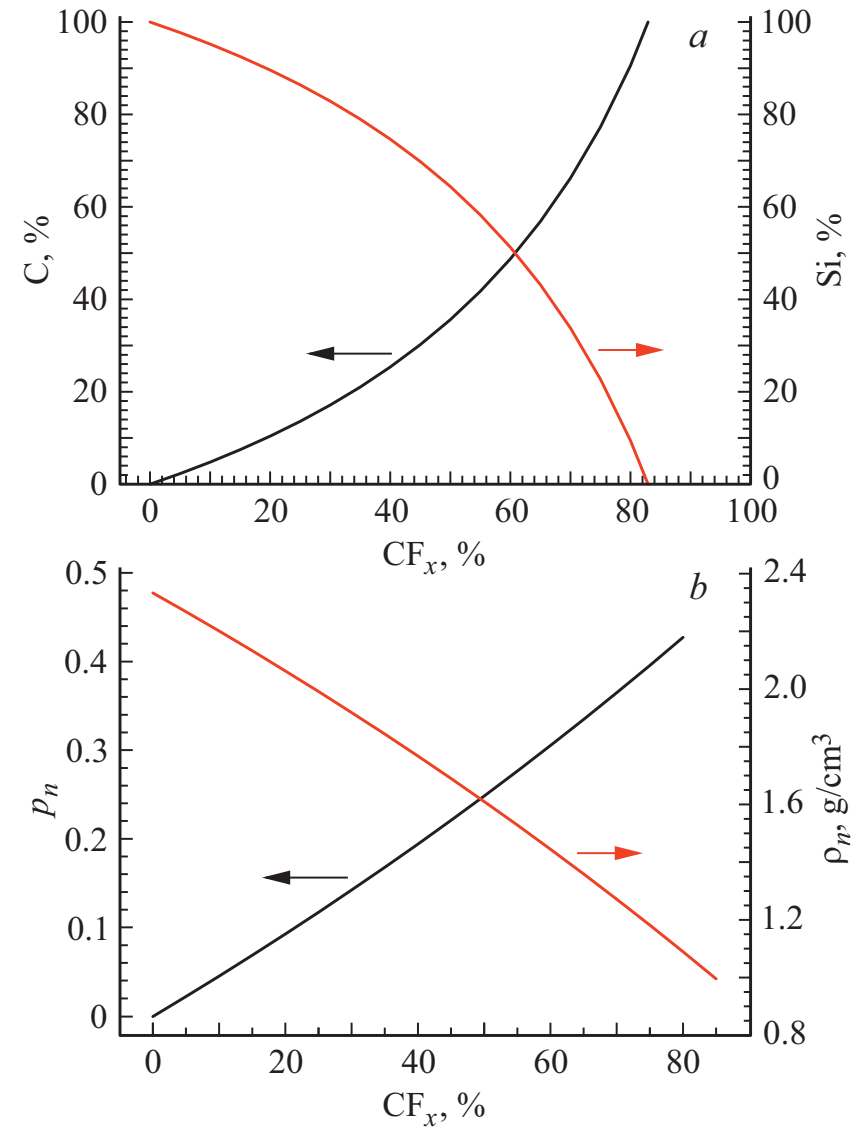

Рис. 2. Расчетные зависимости от массовой доли фторуглерода в исходной смеси: $a$ - содержания углерода и кремния в композитном материале $\mathrm{Si}-\mathrm{C}, b-$ дополнительной пористости $p_{n}$ и условной плотности $\rho_{n}$ компактной части таблетки после отжига.

После отжига в плотных частях таблетки (без макропор) возникают дополнительные полости, обусловленные удалением газообразного продукта, что приводит к уменьшению их плотности. В соответствии с уравнением реакции (3) плотность сохраняющей свой исходный объем смеси должна уменьшиться от $\rho_{\text {mix }}$ до $\rho_{n}$, а общая пористость соответственно возрасти. Дополнительно возникшую пористость обозначим как $p_{n}$. Расчеты показывают, что появление новых пустот и обусловленное этим изменение плотности зависят от количества $\mathrm{CF}_{x}$, добавленного в исходную смесь. Из рис. 2, $a$ видно, что для исходной смеси, содержащей $82.8 \% \mathrm{CF}_{x}$ и $17.2 \% \mathrm{Si}$, весь кремний должен прореагировать с монофторидом углерода, а в твердой фазе останется чистый углерод, плотность которого должна составить $\rho_{n}=1.04 \mathrm{~g} / \mathrm{cm}^{3}$, что по отношению к компактной саже соответствует пористости $p_{n}=44.6 \%$ (рис. 2,b).

Для расчета общей плотности таблеток после отжига $\rho_{f}(r)$ использовались ее начальное значение $\rho_{0}(r)$ и новое значение для условной плотности конечного материала $\rho_{n}(r)$. Вклад новых пор учитывался с помощью формулы $p_{f}=p_{n}\left(100-p_{0}\right)+p_{0}$, где $p_{0}-$ пористость таблетки до отжига. На рис. 3, $a$ приведены экспериментальные значения плотности до и после отжига. Последние сравниваются с расчетными, при этом наблюдается хорошее согласие расчета с экспериментом. Хорошо видно также, что с увеличением доли $\mathrm{CF}_{x}$ кривые $\rho_{0}(r)$ и $\rho_{f}(r)$ расходятся вследствие того, что при большем содержании $\mathrm{CF}_{x}$ образуется большее количество $\mathrm{SiF}_{4}$. С возрастанием содержания $\mathrm{CF}_{x}$ пористость получающихся композитных материалов существенно возрастает, достигая $73 \%$.

Следует заметить, что свободный углерод, остающийся в смеси в соответствии с брутто-реакцией (3), имеет различное происхождение и разную локализацию по отношению к частицам кремния. Это, во-первых, элементарный углерод, содержавшийся в исходном фторуг-
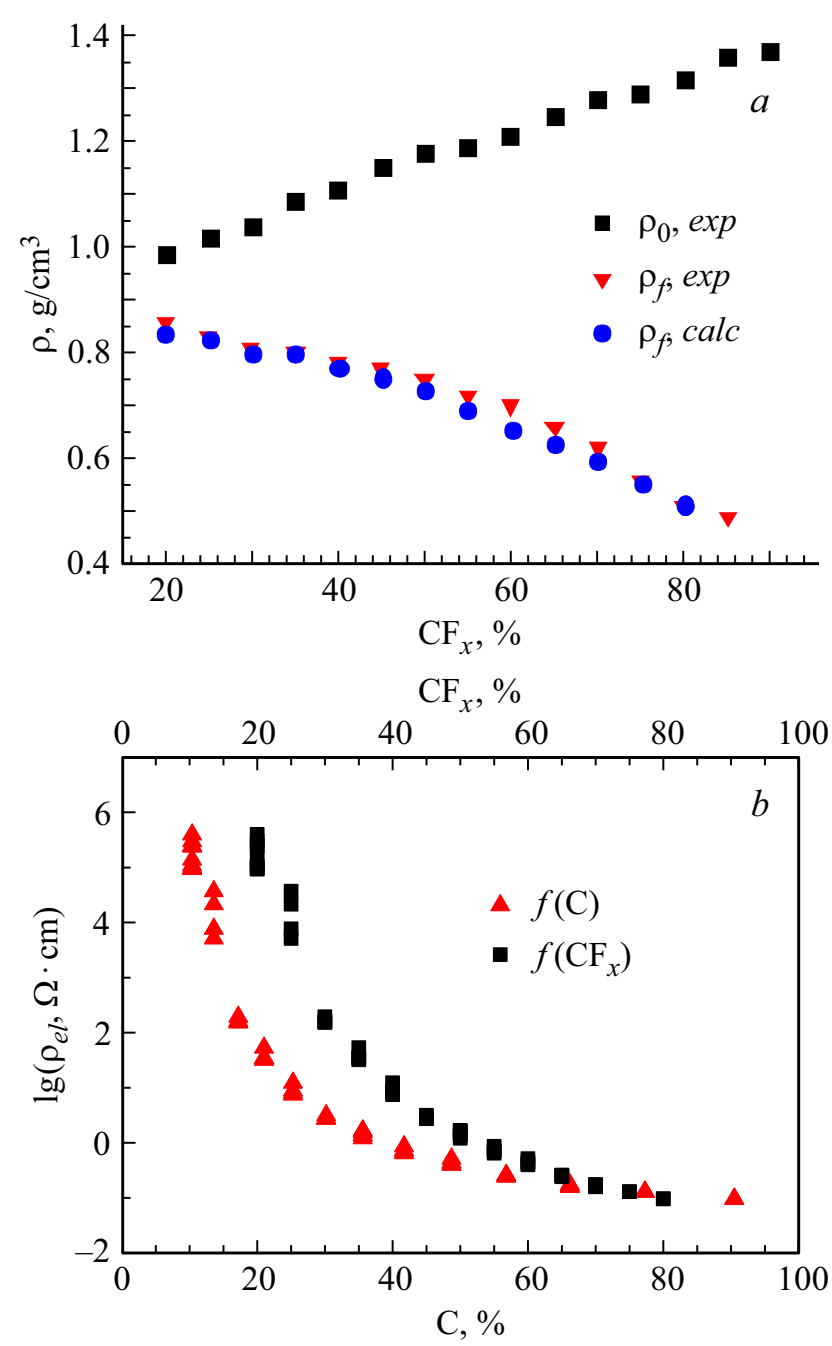

Рис. 3. $a-$ плотность таблеток до и после отжига в зависимости от состава исходной смеси $\mathrm{CF}_{x}+\mathrm{Si}$. Кружками обозначена расчетная плотность, полученная из ее начального значения (до отжига) с учетом появления новых пор; $b-$ зависимость логарифма удельного сопротивления таблетки после отжига от количества в ней углерода и количества фторуглерода в исходной смеси. 
леродном порошке, во-вторых, углерод, образовавшийся в процессе диспропорционирования полимерного монофторида углерода, и, в-третьих, углерод, выделившийся в результате взаимодействия газообразных соединений фтора и углерода с поверхностью кремниевых частиц и создавший таким образом вокруг каждой из них индивидуальную оболочку. В количественном выражении последняя форма углерода является преобладающей. Проведенные эксперименты показали также, что реакция восстановления фторуглеродов кремнием протекает со значительным выделением тепла, настолько, что при достаточно больших объемах исходных смесей (> $150 \mathrm{mg}$ ) с содержанием $\mathrm{CF}_{x} \sim 65-70 \%$ может приводить к взрыву.

Измерение электрического сопротивления полученных композитов проводилось на отожженных таблетках четырехзондовым методом. На рис. $3, b$ приведена зависимость удельного сопротивления $\rho_{e l}$ в полулогарифмическом масштабе от содержания углерода в композите и количества $\mathrm{CF}_{x}$ в исходной смеси. Видно, что по мере возрастания концентрации углерода в композите удельное сопротивление сильно снижается. Добавление к кремнию менее $20 \% \mathrm{CF}_{x}$ оставляет удельное сопротивление на высоком уровне, поэтому интерес представляют образцы, изготовленные из смесей, содержащих $>20 \% \mathrm{CF}_{x}$. Определение типа проводимости отожженных таблеток осуществлялось с помощью термозонда. Bсе полученные образцы имели дырочную проводимость, обусловленную углеродом. Такой тип проводимости присущ углеродным материалам с акцепторными примесями или дефектами, создающими электронные ловушки [6].

Предложенный метод позволяет осуществлять однородную карбонизацию кремниевых наночастиц при одновременном формировании из них нанокомпозитных материалов $\mathrm{Si}-\mathrm{C}$ с иерархической пористой структурой. При этом области между макропорами в изначально спрессованных таблетках заполняются сфероидными наночастицами с кремниевыми ядрами, контактирующими своими оболочками из мелкодисперсного углерода. Такая структура обеспечивает высокую электропроводность получаемых композитов, возрастающую почти на семь порядков при увеличении в них массовой доли углерода от 20 до 90\%. Углерод, выделяющийся на поверхности кремниевых частиц, создает рыхлые, легко деформирующиеся оболочки. Таким образом, заключенные в них $\mathrm{Si}$-наночастицы получают возможность свободно расширяться и сжиматься при циклическом внедрении и экстракции лития без разрушения и потери электрического контакта с окружением.

\section{Благодарности}

Авторы признательны В.В. Жданову и Ю.М. Коштялу за предоставленные для экспериментов порошки нанокремния и фторуглерода.

\section{Конфликт интересов}

Авторы заявляют, что у них нет конфликта интересов.

\section{Список литературы}

[1] Xu Zh.-L., Liu X., Luo Y., Zhou L., Kim J.-K. // Prog. Mater. Sci. 2017. V. 90. P. 1-44.

[2] Ozanam F., Rosso M. // Mater. Sci. Eng. B. 2016. V. 213. P. 2-11.

[3] Liu X., Zhu X., Pan D. // Roy. Soc. Open Sci. 2018. V. 5. P. 172370.

[4] Фиалков А.С. Углерод, межслоевые соединения и композиты на его основе. М.: Аспект Пресс, 1997. С. 377-404.

[5] Астрова Е.В., Воронков В.Б., Нащекин А.В., Парфеньева А.В., Ложккина Д.А., Томкович М.В., Кукушкина Ю.А. // ФТП. 2019. Т. 53. В. 4. С. 540-549.

[6] Уббелоде А.Р., Льюис Ф.А. Графит и его кристаллические соединения. М.: Мир, 1965. С. 114-131, 182. 